\title{
Effective Internal Audit Service Organisation in Health Clinics
}

\author{
Naumova N.A. \\ Kazan Federal University, Institute of Management, Economics and Finance, Kazan, 420008, Russia
}

Kharisova F.I.

Kazan Federal University, Institute of Management, Economics and Finance, Kazan, 420008, Russia

Email: naumovanataliy@mail.ru

\section{Doi:10.5901/mjss.2014.v5n24p170}

\begin{abstract}
Timeliness of this article lies in consideration of internal audit issues in terms of its concentration on medical institutions. We have proposed methods of internal audit service organisation in health clinics and procedure of performance evaluation of this service.
\end{abstract}

Keywords: internal audit, internal audit service, outsourcing, co-sourcing, efficiency of internal audit service performance.

\section{Introduction}

At this stage proprietors, executive management, employees of economical services in the field of large-scale entrepreneurship in Russia already have a notion of internal audit. But speaking about commercial healthcare organisations, internal audit is just being introduced in this sphere. In this regard proprietors, executive management of commercial healthcare centers have questions concerning internal audit, its part in an organisation's operations, functions of internal auditors, effective organisation of internal audit service (hereinafter referred to as IAS), accurate recruitment of staff for this service.

\section{Special Aspects of Internal Audit Service Organisation in Health Clinics}

\subsection{Theory}

Proper internal audit service organisation in healthcare organisations will involve supplementary operating costs. That is why the issue of a way of internal audit organisation throws into sharp relief.

Advantages and disadvantages of different forms of internal audit service organisation are under discussion in the academic community a great while. Three main forms of IAS organisation are commonly known: own service, outsourcing, co-sourcing. Among own IAS advantages we shall mention awareness of a medical establishment's employee in issues of core corporate culture and peculiarities of medical activities, preservation of information in a medical establishment, proficiency of senior executives, operational efficiency, personal interest in improvement of the effectiveness of a medical establishment's activities as IAS is its subdivision. Difficulties of staff recruitment and rising scale of expenditures are significant disadvantages of own audit service organisation in Russian in real life. These disadvantages are neutralized in other forms of internal audit organisation, which have other advantages: flexibility concerning amount of audit personnel, access to advanced technologies and procedures of internal audits, "a fresh eye" on activity of medical establishments. Organisation of IAS in form of co-sourcing or outsourcing also have its disadvantages. Thus, an outresourced expert has more difficulties in obtaining an understanding of peculiarities of medical establishments activities, level of confidence of medical establishments' employees to such expert will be lower than to a member of the staff; lower level of personal interest in improvement of the effectiveness of medical establishment's activities is characteristic of the outresourced expert [1].

There is not a single approach to internal audit organisation. Method of arrangement and structure of the service, number of internal auditors shall be determined individually in every concrete medical establishment as it is rather complicated to specify worthiness of internal audit in one or another organisational form. 
Internal audit experts distinguish following general criteria as guidelines for selection of a method of internal audit organisation:

- a company's risk exposure level;

- readiness of control environment in a company.

They recommend estimating these criteria by expert means.

\subsection{Method}

Frequently, commercial medical establishments do not have experts able to estimate these criteria, as they shall have sufficient competence, experience in the sphere of audit, management, and medicine, in order to express professional judgment. Due to these circumstances, proprietors and executive management have some difficulties in estimation of company's control environment, determination of risks and institution's risk exposure level in the phase of making decision about internal audit organisation in commercial medical establishment. Hereafter, organisations put such estimations in internal audit functions. According to our study of this issue undertaken in commercial medical establishments of the Republic of Tatarstan, we recommend focusing not on the allocated budget but on weight of every abovementioned criterion in the process of internal audit organisation which we offer to estimate using a test suggested by us below. If control environment of a medical establishment is weak and its risk exposure level is high, it appears to be logical to establish own internal audit service. Otherwise it makes sense to organise internal audit in a medical company under the terms of outsourcing.

Definitions "strong" or "weak" control environment, "high or low risk level" are hardly applicable in a scientific research and all the more cannot claim a method convenient for application. In order to develop a test for estimation of a criterion weight we suggest referring to analysis methods. We need to link every criterion to different factors which will have probabilistic connection with this criterion. In capacity of factors we picked questions which we grouped together in Table 1. This Table represents a fragment of the test of selection of the most reasonable form of internal audit organisation for medical establishments. Affirmative answers to suggested questions will give you one point, negative answers will not add any points [2]. In such manner, selecting factors - questions for characterization of readiness of medical establishment's control environment, we take following conditions into account:

- whether establishing discipline for accomplishment of control procedures, acquisition and using of information and communication lines, carrying out monitoring, risk assessment support is available;

- whether control environment is subject to standards;

- whether its procedures, structure, ethical principles are determined;

- whether this element of internal control system depends on internal and external factors including history of a company, its significance (for instance for the country), market, competition, governmental regulation;

- whether it aids in providing efficient management of a company, compliance with legal requirements, asset protection.

Such test is irreplaceable in management of health clinics in the course of internal audit service organisation. Thus, by reference to points in the section "Risk exposure level of a medical establishment" we can estimate that the larger number of points is, the higher risk a medical establishment will be exposed to. Conversely, the larger number of points in the section "Readiness of medical establishment's control environment" is, the readier the medical establishment's control environment is. In such a manner it is possible to define acceptable method of internal audit organisation even not having specialized knowledge шт the sphere of audit or internal audit.

We have illustratively characterized such factor as risk exposure level of a medical establishment by six questions, but it is reasonable to amplify the list of proposed questions. If a medical establishment is presented by a franchise or is a large multi-specialized center, than it is fair to say that in such situation an enterprise is most probably exposed to following risks and losses: slowdown of business activities in consequence of information losses and loss of time caused by imprompt decision making. Exposure of a medical establishment to seasonal decline in demand speaks for customer choice risk. 
Table 1. Test of selection of the most reasonable form of internal audit organisation in commercial medical establishments

\begin{tabular}{|c|c|c|}
\hline $\begin{array}{c}\text { Method of } \\
\text { organization }\end{array}$ & Own IAS & \\
\hline $\begin{array}{l}\text { Factors - } \\
\text { guidelines }\end{array}$ & Questions & \\
\hline 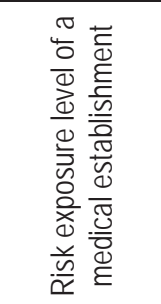 & $\begin{array}{l}\text { - is a medical establishment presented by a franchise? } \\
\text { - is a medical establishment represents multi-specialized medical treatment center? } \\
\text { - are outpatient, surgical, and inpatient treatment provided in this medical establishment? } \\
\text { - is assortment of services rendered is expanded in this medical establishment? } \\
\text { - is this medical establishment exposed to seasonal decline in demand? } \\
\text { - is this assertion correct for your establishment: "less than } 50 \% \text { of professional employees are highly-qualified } \\
\text { or have scientific degrees"? } \\
\text { - other questions. }\end{array}$ & $\begin{array}{l}1 \\
1 \\
1 \\
1 \\
1 \\
1\end{array}$ \\
\hline 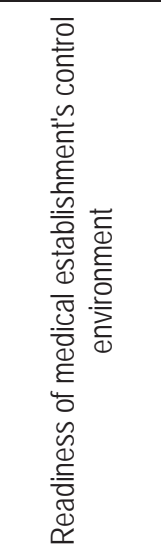 & $\begin{array}{l}\text { - is there a strategy or mission generally accepted in this medical establishment? } \\
\text { - is this assertion correct for your establishment: "have instances of fraud been discovered in this medical } \\
\text { establishment"? } \\
\text { - are control measure for detected violations are applied in the medical establishment under study? } \\
\text { - is there a regimented code of conduct for employees in this medical establishment? } \\
\text { - are policies (procedures) for determination of legal competence for operational commitment developed and } \\
\text { being applied? } \\
\text { - does the medical establishment under study exist at the medical service market over } 3 \text { years? } \\
\text { - is this assertion correct for your establishment: "average bill of a patient amounts to less than } 4,000 \text { rubles"? } \\
\text { - is this assertion correct for your establishment: "the establishment does not suffer staff shortage with increase } \\
\text { of number of patients every month"? } \\
\text { - whether general taxation system is applied in the medical establishment? } \\
\text { - were facts of sales of services by putting pressure on patients discovered in the medical establishment under } \\
\text { study? } \\
\text { - other questions }\end{array}$ & $\begin{array}{l}1 \\
1 \\
1 \\
1 \\
1 \\
1 \\
1 \\
1 \\
1 \\
1\end{array}$ \\
\hline
\end{tabular}

Thus and so, affirmative answers to these questions are indicative of risk exposure of a medical establishment, and negative answers speak for absence of any risks for activities.

Readiness degree of medical establishment's control environment can be characterized by variety of factors such as medical company's history, competence and experience level of medical and administration staff, way of thinking of a managerial staff concerning management, methods of distribution of authority and duties, organisational culture, taxation system, amount of services rendered.

\section{Estimation of Efficiency of Internal Audit Service in Health Clinics}

\subsection{Theory}

Modern management of commercial medical establishments presupposes estimation of efficiency of performance of all its subdivisions including, with higher priority, internal audit service. Besides, International Standard for the Professional Practice of Internal Auditing (hereinafter referred to as the IIA standard) 1300 - Quality Assurance and Improvement Program includes a subsection devoted to control of efficiency in the order of internal and external check[3].

Let's get down to a complicated and multifaceted definition of a term "efficiency" which relates to production, economic, and other processes of an enterprise. Efficiency shall be understood to mean performance of a process, operation, or project, defined as connection of the effect or the result with expenditures which determined obtaining of such results. Internal audit efficiency lies in the fact that all activities of the internal audit service (division, department, office), from its organisation to its results, shall be conducted with minimal costs, maximal performance, and in accordance with the best practices [4].

Procedure for determination of internal audit efficiency in commercial enterprises is the subject of wide speculation in the academic community. At the moment the legislation does not have a definite set of highlight figure enabling to hand down an opinion concerning efficiency of internal audit subdivision activity in a commercial establishment, including a medical one, although issues of internal audit activity efficiency are considered in Practical Instruction to IIA standards 
1300 - Quality Assurance and Improvement Program, 1310 - Requirements of the Quality Assurance and Improvement Program, 1311 - Internal Assessments, 1312 - External Assessments.

Necessity of determination of internal audit activity efficiency is confirmed by variety of factors. Significant changes are in process in establishments which internal audit efficiency has been assessed, and these changes are expressed in: boost in confidence in internal audit; increase of furnished guarantees and consults quality; discovery of the service efficiency enhancement potential; internal audit cost reduction. Thus and so, estimation of internal audit subdivision efficiency promotes profession of internal auditor and overall internal audit functioning to the higher level of quality [5].

IAS performance assurance falls within competence of IAS manager, that is why responsibility for IAS performance is rested upon this manager and a head of this organisation. As proprietors and management of commercial establishments, particularly medical establishments, are interested in effective internal audit functioning, development of efficiency determination procedure, which would include issues of organisation and key indicators, turns to be essential. Structure and target value of indicators of IAS performance evaluation shall be developed by its manager and shall be approved by a proprietor of the business. Internal audit experts are advised to define IAS efficiency at the moment of its arrangement and no less frequently than once every five years afterwards[6].

\subsection{Method}

We propose to adapt and improve segmental efficiency method for medical establishments. The fundamental idea of this method consists of direct determination of the effect which is estimated according to reports of an internal auditor and correlates with expenditures. Among disadvantages of this method we shall mention difficulties arisen in the process of its application: difficulties in designation of an input cost of one labor hour of an internal auditor, segments for efficiency calculations, estimation of results of execution of every internal auditor's task in terms of direct, indirect, and prospective effect. And these difficulties are caused by absence of a general efficiency indicator, as the authors calculate the effect in money terms.

We turn our attention to peculiarities and initial arguments which shall be taken into account in adaptation of the method of determination of internal audit service efficiency with respect to medical private establishments as well as to problems we faced in the course of work. On the grounds of the undertaken study of generation of internal audit functions we have arrived at the conclusion that it is reasonable to perform internal audit in commercial medical establishments by arrangement of own internal audit service, and in form of outsourcing - in small diagnostic centers and dental hospitals. Another important argument in the process of development of internal audit activity efficiency in a medical establishment is that internal audit generation in a commercial medical organization as well as its functioning involve assessment of costs. They will compose an input cost of considered services. Thus and so, an input cost of one labor hour of an internal auditor in a medical establishment can be determined by means of dividing of expenditures for organisation and functioning of an internal auditor by number of his/her working hours. We also propose to withdraw from calculation of the internal auditors work effect by segments for evening-out of abovementioned disadvantages, as medical establishments fall into the category of small and medium-sized enterprises and their organisational arrangement is quite simple. As for profitableness (direct economic effect) provided by internal audit, we suggest to measure it with the aid of a "profit" arisen from "actualization" of internal auditors' consults, i.e. from savings arisen from usage of own services. It stands to mention the main problem which is faced by researchers attempting to measure efficiency of internal audit activities quantitatively. It lies in uncertainty of determination of an "income" of internal auditor's activities, as technically his/her services do not materialize in their pure form. Internal audit experts distinguish a variety of causes preventing estimation of efficiency of internal audit service in an establishment's activities:

- before everything else, internal auditors are engaged in estimation of weak spots of medical establishments' activities and provision of recommendations, rather than calculation of their works results' value;

- imperceptible presence of internal audit service often prevents unwanted events (for example, fraud, corrupt practices);

- certain, and sometimes a greater part of internal audit service's recommendations can not be directly measured by its quality (for instance, improvement of a company's image);

- results of internal audit are frequently implicit, or a long period of time passes between the audit and appearance of notable results [8].

In connection therewith, income of internal auditor's activities in a commercial medical establishments is contingent, so we name it a "contingent income".

However it should be noted that expenditures prepaid into internal audit can be easily determined. Audit service 
implementation budget will include three key cost items: wage of internal auditors, insurance contributions, and cost of acquisition and implementation of programs and equipment. Monthly costs for internal audit functioning in efficiency ratio determination are included in full measure. But the question about amount of inclusion of organisational costs in calculations arises. There is not unambiguous answer to the question on which pay-off period we shall focus on. Western financial institutions are ready to consider projects with 7-8 years pay-off periods, Russian banks give preference to projects with pay-off periods for up to 3 years. Focusing on the Russian banking system we recommend to accept three years as an ordinary pay-off period of internal audit organisation.

Let us subdivide costs for internal audit organisation and functioning in a commercial medical organisation in current monthly costs (Ci) and capital costs, i.e. costs carried out in the process of generation of an internal audit function (Cs).

Further, we shall determine a "contingent income" of IAS activities in a medical establishment in money terms. We suggest to calculate the "contingent income" on the assumption of internal auditors' inspection reports. Economic effect of implemented recommendations, saved resources, cut down risks, losses averted shall also be included into the "contingent income" of the internal auditor activity in a medical establishment irrespective of evaluation method for this figure.

Table 2. List of internal audit estimated figures

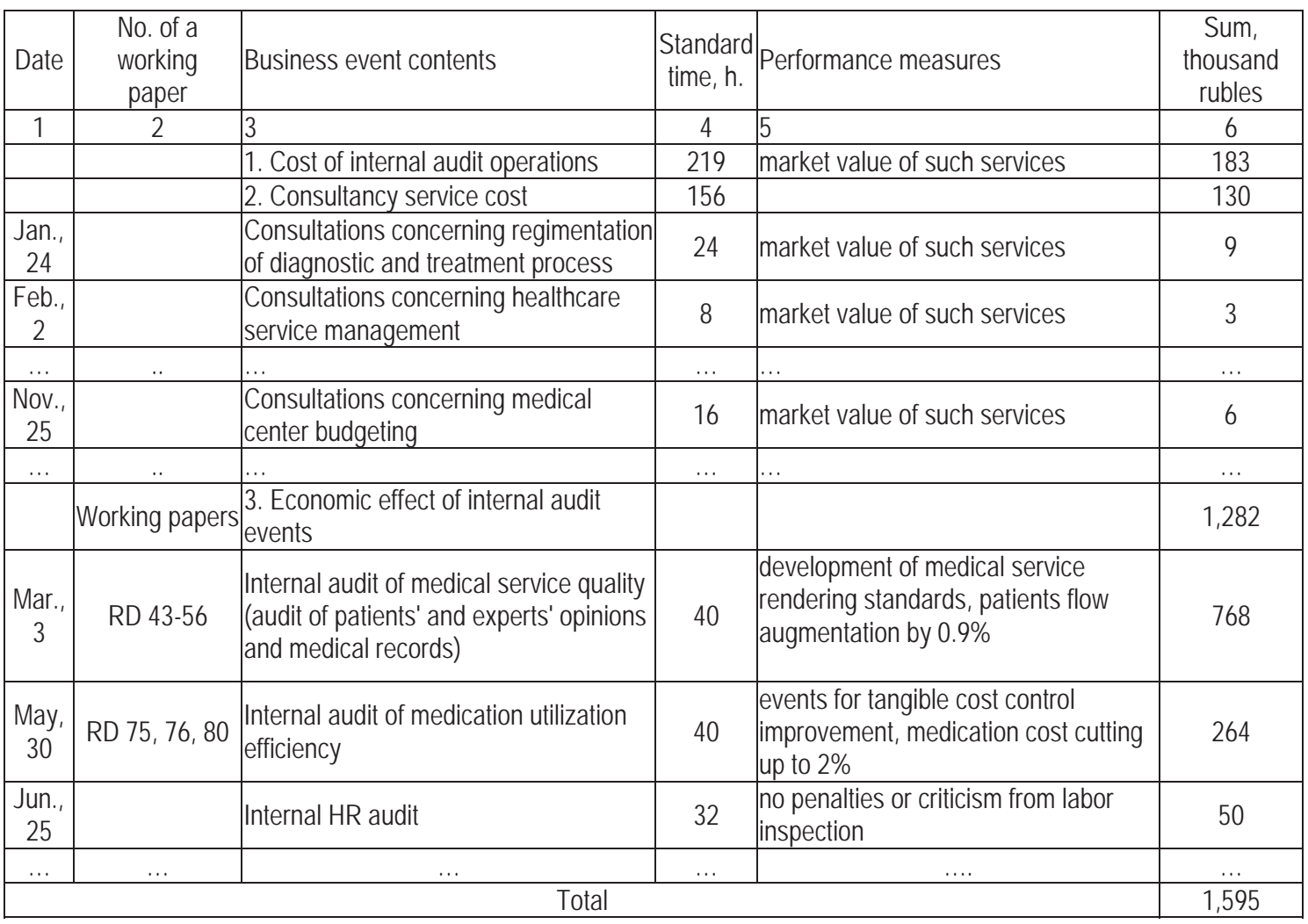

\subsection{Result}

Thus, formulas for determination of an annual aggregate "contingent income" can be presented as follows:

le is an income expressed in the amount of economic effect from internal audit events.

$I=\sum I e+\sum I r,(1)$

where Ir is an income calculated on the assumption of internal auditors' reports;

le is an income expressed in the amount of economic effect from internal audit events.

We recommend to reflect information about income from rendering of internal audit services in medical establishments for one year in cumulative form separately for each IAS employee, area of activity in the next internal audit working document which is presented in Table 2 . 
Thus, the formula for determination of economical efficiency of internal audit institute activities in medical establishments shall be presented with due regard to time estimate of carried out costs and "contingent income" of organisation and activities of IAS in medical establishments. It will be as follows:

$$
\mathrm{K}=\frac{\sum_{t=0}^{T}\left(A_{t}-3 i_{t}\right)(1+r)^{-t}}{\sum_{t=0}^{T} 3 s_{t}(1+r)^{-t}},(2)
$$

where $\mathrm{K}$ is an economical efficiency ratio;

$\mathrm{T}$ is a pay-off period for internal audit service organisation;

$t$ is a number of a time step;

$r$ is a discount coefficient.

\section{Conclusion}

Approaching examination of international standards for the professional practice of internal auditing, studies of western and Russian scientists, as well as the best western and native practice from a critical standpoint, we have specified the procedure for determination of internal audit efficiency in the light of specific features of medical establishments. Among advantages or the suggested method we can distinguish applicability of this method in medical establishments which do not get profit and high analytic property of obtained results. At that this is particularly important that our algorithms of determination of internal audit efficiency in medical establishments will not be limited to theoretical development but find their practical use. Determination of IAS efficiency in medical establishments' practice allows to reach the best possible internal audit organisation not only from the perspective of its methodology, but also in the context of economical efficiency [9].

\section{References}

Naumova, N.A. Internal audit of the activities of commercial health clinics // Lobachevsky State University of Nizhni Novgorod, thesis, 2013. pp. 14-15

Naumova, N.A. Organization of internal audit in health clinics// In the Proceedings of the 2011 international scientific-practical conference in Przemysl, 2011. pp. 8-12

Practical Instructions to International Standards for the Professional Practice of Internal Auditing // translation of Practical Instructions as amended on June 1, 2011.www.iia.ru

Jean Pierre Garitte Materials of the report "Internal Auditor Performance Evaluation" Opening of regional center of Russian Institute of Internal Auditors in the city of Kazan, November 6, 2011

J. Wiela. Internal audit: leave or stay? // gaap.ru/articles/49699/ ACCA Russia/, 20 August 2009.

Vyalkov A.I. Theoretical and Organizational and Methodological Aspects of reduction of risks in medical practice // Healthcare Control Issues, 2(27) , 2006. pp. 52-57

Federal Law On Fundamental Healthcare Principles in the Russian Federation dated November 21, 2011.\#323-FZ

Vishnyakov N.I., Minayev V.A., Danilov V.O. Health Economics. Chemistry Research and Development Establishment of St. Petersburg State University, 2000.

Thomas Barela The Need for Internal Audit in Healthcare Organizations // Healthcare industry pulse, 2005.

Khismatullin B.R. and Kharisova F.I. Insurance as a Way for Reducing the Market Risks Level. World Applied Sciences Journal 31 (6): 1188-1190, 2014. DOI: 10.5829/idosi.wasj.2014.31.06.93

Kharisova F.I. and Rakhmanova I.I. Sampling in Tax Audit. World Applied Sciences Journal 31 (1): 138-142, 2014. DOI: 10.5829/idosi.wasj.2014.31.01.14285.

Badara, M.S., Saidin, S.Z. (2014)/ Internal audit effectiveness: Data screening and preliminary analysis. Asian Social Science, 10 (10), pp. 76-85.

Stanciu, V. (2014). Internal audit universe develoments - corporate social responsibility and sustainable developmemt. Quality - Access to Success, 15 (SUPPL.1), pp. 318-322.

Shan, Y.G. (2014). The impact of internal governance mechanisms on audit quality: A study of large listed companies in China. International Journal of Accounting, Auditing and Performance Evaluation, 10 (1), pp. 68-90.

Bingaman, D., Kaplan, L. (2014). Internal audit advice for nurse practitioner advocacy groups.tNurse Practitioner, 39 (2), pp. 14-15. 